\title{
English communication skills for prospective English teachers in Japan
}

\author{
Yuichi Todaka \\ Department of Intercultural Studies, Miyazaki Municipal University, Japan \\ https://doi.org/10.36505/ExLing-2010/03/0048/000168
}

\begin{abstract}
The objectives of this study are twofold: (1) to promote necessary English oral skills; and (2) to provide prospective English teachers with a necessary roadmap towards achieving competency in English oral communication skills. Prospective English teachers at 11 Japanese universities participated, and we tested our text materials in terms of the degree of motivation, and of the progress on their English oral communication skills. Based upon the obtained results, our text materials helped our participants improve their motivation towards English study and their English oral communication skills. Various modifications that have to be made to the text materials for our next project were also found, however.
\end{abstract}

Key words: listening, speaking, motivation, self-assessment checklist

\section{Introduction}

Todaka (2009) and Todaka and Misono (2009) reviewed the major articles on second language acquisition, English education, and English phonetics published both in Japan and in overseas during the last two years to pinpoint the theoretical constructs, techniques and methods that are common among the articles reviewed. Based on their findings, various exercises focusing on those constructs were developed and customized to help our students develop necessary English oral communication skills.

In addition, another significant factor considered in this project is the issue of motivation. Dornyei and Csizer $(2002,2006)$ promulgated the notion of L2 Motivational Self System based on their findings. Its core constructs are (1) ideal self, which is defined as the attributes someone would ideally like to possess, (2) out-to self, attributes that one believes one need to have, and (3) L2 learning experience.

Thus, Todaka (2009) formulated a questionnaire assessing Japanese EFL learners' concept of their Ideal L2 Self and motivated learning behavior based on Dornyei and Csizer' (2006) study. However, the number of participants in his study was limited so that only tentative conclusions could have been made. Thus, we utilized the same questionnaire in the present project to reconfirm if the same or similar tendencies could be found.

In addition, the ideal self concept described above needs to come as part of an imagery component and a repertoire of appropriate plans, scripts, and self-regulatory instructional avenues, which are methodological in nature.

ExLing 2010: Proceedings of 3rd Tutorial and Research Workshop on Experimental Linguistics, 25-27 August, Athens, Greece 
We therefore focused our attention on the significance of long-term commitment to L2 learning, as the amounts of time EFL learners engage in L2 learning in class are limited, so that EFL learners need training to become autonomous learners.

\section{Methodology}

345 prospective English teachers participated in the present study. 12 to 15 sessions, dependant of the curriculum of each university, for this project were conducted once a week from April through July in 2009. Each session lasted 90 minutes.

A self-assessment checklist was created based upon essential phonetic features, and a questionnaire was administered twice, during the outset of the class and at the end of the class to examine how well the participants had understood each item. In addition, we also formulated a questionnaire aiming to assess factors in L2 learning. The objective of this questionnaire was to evaluate our participants' concept of 'Ideal L2 Self' and their motivated behaviour.

Furthermore, we had the participants take the same TOEIC listening test at the outset and at the end of the semester to examine their improvements in their English listening skill. In addition, we selected 25 out of 345 subjects to assess their improvements in their English speaking skill. The speaking tasks were formulated based upon a TOEFL speaking test and the assessment scale was developed based upon UCLA oral proficiency test for non-native TAs (Celce-Murcia et al, 1996: 404).

\section{Results and discussion}

The constructs of instrumentality, language anxiety, classroom anxiety, language learning attitude, attitudes towards L2 community, Out-to L2 self, and ideal L2 self were supported by our participants. Furthermore, the lack of motivated learning behaviour and linguistic self-confidence were also found. However, the participants indicated that they had experienced varying degrees of anxiety in L2 communication, and that they did not have confidence in their linguistic abilities. Furthermore, they also indicated that they did not consider themselves to be diligent language learners.

Second, the results of our checklist criteria were examined. Scores of all the checklist criteria improved, which in turn indicates significant improvements in the understanding of the text materials. Nonetheless, the sections of sentence stress and of English intonation in our textbook materials were found to need further modifications.

Third, we examined the TOEIC test scores taken at the outset and at the end of the training sessions. 345 students took both the pre-and post TOEIC 
tests. Based upon an ANOVA analysis, the difference in scores between the pre-and the post TOEIC tests was found to be significant at the 99\% confidence level $(\mathrm{p}<.0001, \mathrm{~F}=24.43)$. However, the same test was utilized twice; thus, the obtained results might have been different if different tests were administered.

Finally, we examined the results of the speaking performance ratings of 25 randomly selected subjects, and the subjects had to answer the questions on the following four tasks: (1) personal preferences; (2) choices; (3) school matters; and (4) academic matters.

It became apparent that Task 4, which required the subjects to understand the given listening material and to summarize what had been described in the listening material, was found to be most difficult. Although practice exercises were tailored to promote our participants' oral communication skills, the number of carefully planned and customized exercises had not been enough.

Having examined all the data, we can say that (1) enjoyment derived from language learning in the classroom and learning how to study on their own by exploiting the available L2 learning opportunities are the keys to helping Japanese college students relieve their learning anxiety and to helping them realize the significance of making efforts and of having strong persistence in L2 learning to realize their ideal L2 self-images; (2) Japanese prospective English teachers are interested in improving their oral communication skills; (3) our participants listening skill significantly improved based on TOEIC listening test scores; and (4) significant improvements in our participants' speaking skill were found. However, the following factors were found to be important for reconsiderations for our next project: (1) some of the exercises in the textbook were not suitable for our participants in terms of the degree of difficulty and usefulness. This was especially true of the exercises in the sections of sentence stress and of intonation; (2) different TOEIC tests need to be utilized to truly understand the efficacy of our pedagogical approach to improving our participants' English listening skill; (3) more spoken samples need to be examined to understand the efficacy of our pedagogical approach to improving our participants' speaking skill; and (4) much more care needs to be taken for recordings, as some of the recordings by American and Australian English speakers misread their readings.

\section{Conclusion}

This is the second year of our three-year longitudinal study of helping prospective English teachers improve their English oral communication skills. We created various exercises to justify one of the aims; that is, developing oral communicative competency, mentioned above. The results we obtained seem promising in the sense that our participants' listening and 
speaking skills significantly improved and that our checklist criteria helped our participants understand the essential constructs indispensable to improving their oral communication skills. Nonetheless, various modifications to our original text material, based upon the participants' responses, have to be developed for our next project.

We believe that our understanding of developing effective L2 oral communication skills will open up new avenues for empirical inquiry in this domain as we test the limits of our pedagogy, and stretch beyond further boundaries.

\section{References}

Celce-Murcia, M., Brington, D., Goodwin, J. 1996. Teaching pronunciation: A reference book for teachers of English to speakers of other languages. NY: Cambridge University Press.

Dornyei, Z., Csizer, K. 2002. Some dynamics of language attitudes and motivation: Results of a longitudinal nationwide survey. Applied Linguistics 23 (4): 421-462.

Dornyei, Z., Csizer, K., Nemeth, N. 2006. Motivation, language attitudes and globalization: A hungarian perspective. Clevedon: Multilingual Matters.

Todaka, Y. 2009. Daini gengo shutokuriron no matome: kokusaihen. Journal of English Phonetics, 13: 395-406.

Todaka, Y., Misono, K. 2009. Daini gengo shutokuriron no matome: kokunaihen.. Journal of English Phonetics, 13: 407-418. 